\title{
Validation of indicators used to assess unconsciousness in veal calves at slaughter
}

\author{
M. T. W. Verhoeven ${ }^{1,2+}$, M. A. Gerritzen ${ }^{1}$, L. J. Hellebrekers ${ }^{3}$ and B. Kemp ${ }^{2}$ \\ 'Livestock Research, Wageningen University and Research Centre, P.O. Box 338, 6700 AH Wageningen, The Netherlands, ${ }^{2}$ Adaptation Physiology Group, \\ Department of Animal Sciences, Wageningen University, P.O. Box 338, 6700 AH Wageningen, The Netherlands; ${ }^{3}$ Faculty of Veterinary Medicine, Utrecht Unversity, \\ P.0. Box 80154, 3508 TD Utrecht, The Netherlands
}

(Received 1 June 2015; Accepted 7 February 2016; First published online 11 March 2016)

\begin{abstract}
European legislation states that after stunning regular checks should be performed to guarantee animals are unconscious between the end of the stunning process and death. When animals are killed without prior stunning these checks should be performed before the animal is released from restraint. The validity of certain indicators used to assess unconsciousness under different stunning and slaughter conditions is under debate. The aim of this study was to validate the absence of threat-, withdrawal-, corneal- and eyelid reflex as indicators to assess unconsciousness in calves subjected to different stunning and slaughter methods. Calves (201 $\pm 22 \mathrm{~kg}$ ) were randomly assigned to one of the following four treatments: (1) Captive bolt stunning followed by neck cut in an inverted position ( $\mathrm{n}=25)$; (2) Non-stunned slaughter in an upright position ( $\mathrm{n}=7)$; (3) Non-stunned slaughter in an inverted position (180 rotation) $(\mathrm{n}=25)$; (4) Non-stunned slaughter in an upright position followed by captive bolt stunning $40 \mathrm{~s}$ after the neck cut $(\mathrm{n}=25)$. Each calf was equipped with non-invasive electroencephalogram (EEG) electrodes before the slaughter procedure. All reflexes were verified once before the slaughter procedure. At the beginning of the procedure $(T=0 \mathrm{~s})$ calves were stunned (treatment 1) or neck cut in an upright position (treatment 2, 4) or inverted position (treatment 3). Calves of treatment 4 were captive bolt stunned $34 \pm 8 \mathrm{~s}$ after the neck cut. Reflexes were assessed every $20 \mathrm{~s}$ from $T=15 \mathrm{~s}$ for all treatments until all reflex tests resulted in a negative response three times in a row and a flat line EEG was observed. In addition, reflexes were assessed $5 \mathrm{~s}$ after captive bolt stunning in calves of treatments 1 and 4 . Visual assessment of changes in the amplitude and frequency of EEG traces was used to determine loss of consciousness. Timing of loss of consciousness was related to timing of loss of reflexes. After captive bolt stunning, absence of threat-, withdrawal-, corneal- and eyelid reflex indicated unconsciousness as determined by EEG recordings. After non-stunned slaughter, both threat- and withdrawal reflex were on average lost before calves were unconscious based on EEG recordings. The eyelid-and corneal reflex were on average lost after calves had lost consciousness based on EEG recordings and appeared to be distinctly conservative indicators of unconsciousness in non-stunned slaughtered calves since they were observed until $76 \pm 50$ and $85 \pm 45 \mathrm{~s}$ (mean $\pm S D$ ), respectively, after EEG-based loss of consciousness.
\end{abstract}

Keywords: electroencephalogram, calves, reflexes, slaughter, (un)consciousness

\section{Implications}

Monitoring unconsciousness at slaughter is mandatory by European legislation and is often determined by the absence of behavioural indicators (i.e. loss of posture), physical signs (i.e. rhythmic breathing) and reflexes. Previous research in sheep has indicated that the absence of certain reflexes at slaughter is not a reliable indicator of unconsciousness. The present study showed that absence of the withdrawal- and threat reflex did not indicate unconsciousness in veal calves

\footnotetext{
${ }^{\dagger}$ E-mail: merel.verhoeven@wur.nl
}

subjected to non-stunned slaughter and are therefore not recommended for assessment of unconsciousness. Absence of the eyelid- and corneal reflex, on the other hand, reflected unconsciousness well and are considered acceptable for assessment of unconsciousness during non-stunned slaughter.

\section{Introduction}

Animals are stunned before slaughter to minimize pain and distress as required by European law (Council Regulation (EC) No 1099/2009, 2009). Stunning, however, is not always 
compatible with specific methods of slaughter prescribed by religious rites and is legally determined not to be mandatory in animals subjected to this type of slaughter (Council Regulation (EC) No 1099/2009, 2009). Stunning after neck cutting is practiced in some European countries in preference to no stunning at all to avoid potential animal welfare problems (Farouk, 2013). Assessment of unconsciousness is a legal requirement during the slaughter process in Europe irrespective of the method used (Council Regulation (EC) No 1099/2009, 2009). During non-stunned slaughter, animals are restrained and bled by a transverse incision of the neck, severing the skin, muscles, trachea, oesophagus, carotid arteries, jugular veins and major nerves. The severe decrease in cerebral blood flow is intended to lead to a rapid onset of disorganized brain function and unconsciousness (Mellor et al., 2009). In comparison to sheep, consciousness after the neck cut is prolonged in cattle, because the vertebral arteries, which are not severed by the neck cut, continue to supply blood to the circle of Willis and provide some blood to the brain (Baldwin and Bell, 1963). There is considerable variation between cattle in time to loss of consciousness after the neck cut. Some studies suggest a rapid loss of consciousness (4 to $7 \mathrm{~s}$ ) in cattle after the neck cut (Nangeroni and Kennett, 1963; Bager et al., 1992) whereas other studies report a spontaneous loss of brain activity $75 \pm 48 \mathrm{~s}$ after the neck cut (range 19 to $113 \mathrm{~s}$ ) and the possibility of an intermittent return to consciousness for up to 123 to $323 \mathrm{~s}$ after slaughter (Newhook and Blackmore, 1982; Daly et al., 1988). There is substantial debate about which indicators most adequately assess unconsciousness at slaughter and which merit further investigation (European Food and Safety Authority (EFSA), 2013). The use of recorded brain activity (as presented in an electroencephalogram (EEG)) is considered to be the most objective method available for assessing unconsciousness and is generally accepted as the current 'gold standard' (Erasmus et al., 2010; EFSA, 2013; Verhoeven et al., 2015a). Due to the complexity of collecting EEG data at slaughter, absence of behavioural indicators (i.e. loss of posture) physical signs (i.e. rhythmic breathing) and reflexes (i.e. righting-, threat-, withdrawal-, corneal- and eyelid reflex) is often used to assess unconsciousness. However, there is a lack of scientific publications reporting relationships between unconsciousness ascertained by EEG recordings with those assessed using behavioural indicators, physical signs or reflexes that could be used in slaughterhouse conditions in bovines. It has been formally agreed in the Netherlands that animals subjected to non-stunned slaughter should be unconscious within $40 \mathrm{~s}$, based on absence of at least three of the following five indicators: (1) threat reflex; (2) withdrawal reflex; (3) corneal reflex; (4) (spontaneous) eyelid reflex; (5) rhythmic breathing (Staatscourant, 2012). Different studies showed that the corneal- and eyelid reflex and rhythmic breathing were lost long after animals were considered unconscious based on EEG recordings, making them distinctly conservative indicators when assessing unconsciousness in non-stunned slaughtered sheep (Verhoeven et al., 2015b) and veal calves (Lambooij et al., 2012). On the contrary, both threat- and withdrawal reflex were often lost before sheep were unconscious according to EEG recordings during non-stunned slaughter (Verhoeven et al., 2015b). The objective of the current study was to assess absence and presence of the following indicators: threat-, withdrawal-, corneal- and eyelid reflex, and determine their relationship to (un)consciousness as identified by EEG recordings during stunned and non-stunned slaughter in veal calves.

\section{Material and methods}

\section{Approval}

This study was approved (DEC 2014045.b) by the Ethical Committee of the Animal Sciences Group of Wageningen UR, The Netherlands and in compliance with Dutch legislation.

\section{Experimental set-up}

On seven occasions, calves subjected to (non)stunned slaughter were observed at an abattoir in the Netherlands in the period from September to November 2014. Eighty-two cattle of mixed breeds (warm carcass weight $201 \pm 22 \mathrm{~kg}$ ) were randomly selected from groups in lairage and held individually in a rotation box (Nawi, Borculo, the Netherlands) while equipped with non-invasive EEG electrodes. Calves were randomly assigned to one of the following four treatments: (1) Captive bolt stunning (Cash Magnum 9000 s) followed by neck cut within $30 \mathrm{~s}$ in an inverted position (180 $0^{\circ}$ rotation) $(n=25)$; (2) Non-stunned slaughter in an upright position ( $n=7)$; (3) Non-stunned slaughter in an inverted position ( $180^{\circ}$ rotation) $(n=25)$; (4) Non-stunned slaughter in an upright position followed by captive bolt stunning $40 \mathrm{~s}$ after the neck cut $(n=25)$. Treatment group 2 was limited to seven calves because of animal welfare concerns: that is delayed induction of unconsciousness due to insufficient bleeding. Calves were restrained with a head yoke and chin lift, but without a belly supporting plate. The neck cut was performed as a clean transverse incision of the neck, severing the skin, muscles, trachea, oesophagus, carotid arteries, jugular veins and major nerves. All stunning and slaughter procedures were performed by the same skilled halal slaughter man.

\section{Electroencephalogram recordings}

After being positioned in the restrainer, the head of the animal was shaved with an electrical trimmer (Aesculap favorita II GT104, Braun Suhl GmbH, Germany) to enable placement of EEG electrodes. Thereafter, an elastic halter was placed around the calves head. A cross-shaped piece of cotton was attached to the halter containing Velcro parts at each end of the cross. A 'shooting-hole' was cut in the middle of the cross, through which the captive bolt could be administered. Five rubber sensor carriers were placed around the 'shooting-hole' (Figure $1 \mathrm{a}$ and b). Five $\mathrm{Ag} / \mathrm{Cl}$ pellet electrodes (Twente Medical Systems International (TMSi), Oldenzaal, The Netherlands) were placed in the rubber sensor carriers to make contact with the shaved skin of the calf. Each electrode was wrapped in a small sponge soaked in saline solution, which served as interface with the skin. 
(a)

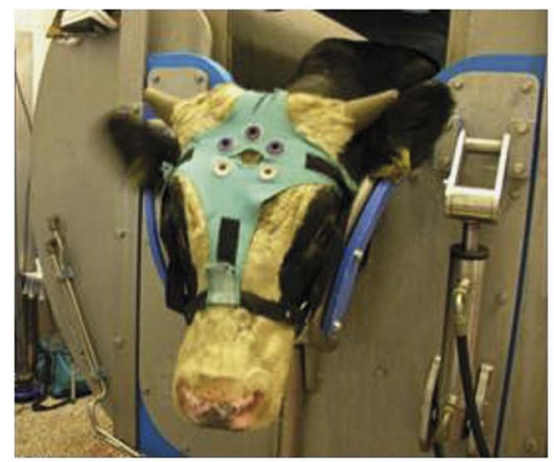

(b)

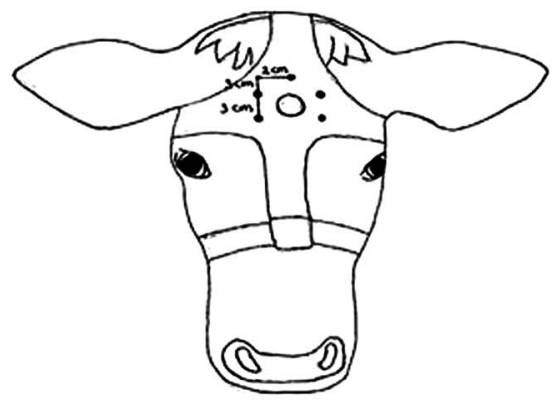

Figure $1(a, b)$ Electroencephalogram (EEG) electrode placement on a veal calf.

One electrode was placed over the frontal bone, on the sagittal midline on a line extending between the base of both ears. Two electrodes were placed $2 \mathrm{~cm}$ left and right from the sagittal midline and $3 \mathrm{~cm}$ frontal to the first electrode, the other two electrodes were placed $2 \mathrm{~cm}$ left and right from the sagittal midline and $6 \mathrm{~cm}$ frontal to the first electrode. An elastic band was wrapped once around the calves' head to secure the upper three electrodes, but leaving the ears and eyes free to move. All electrodes were connected via a $140 \mathrm{~cm}$ active shielded cable to the 32-channel Porti recording system (TMSi). Porti uses bipolar amplifier technology with high input impedance $(>1 \mathrm{G} \Omega$ ) that amplifies the potential difference between pairs of electrodes. The input amplifier is dimensioned as a multichannel instrumentation amplifier. Electrode impedance was $<5 \mathrm{k} \Omega$. The EEG was displayed with a band pass filter of 0.5 and $30 \mathrm{~Hz}$, respectively, and raw, unfiltered, data were saved directly onto a computer. Sample rate was set at $0.5 \mathrm{kHz}$. Once the electrodes had been positioned correctly and a good live signal had been established, baseline EEG activity was recorded for at least $2 \mathrm{~min}$. At the beginning of the slaughter procedure $(T=0 \mathrm{~s})$ calves were stunned (treatment 1 ) or neck cut in an upright position (treatment 2,4 ) or inverted position (treatment 3). Calves of treatment 4 were captive bolt stunned $34 \pm 8 \mathrm{~s}$ after the neck cut. The EEG was recorded until a flat EEG ( $<10 \%$ baseline amplitude) was observed and all reflexes showed absence of response that was repeated sequentially three times. Hereafter, the equipment was carefully removed from the calf after which it was released from the restrainer to allow further processing of the carcass.

\section{Measurements around stunning and slaughter}

The threat-, withdrawal-, corneal- and eyelid reflex were verified once before the slaughter treatment started. The threat reflex was assessed by checking the presence of a blinking reaction to an abrupt movement of the index finger towards the eye ball without touching the eye. The withdrawal reflex was studied by pinching the calves nose between two fingertips and determining whether or not it responded with a withdrawal of the nose or head. In case of non-stunned slaughter only withdrawal of the nose could be observed after the neck cut. The corneal reflex was assessed by a gentle touch of the cornea with the index finger, and the presence/absence of a blinking reaction was recorded. The eyelid reflex was assessed by a gentle touch of the eyelid, and the presence/absence of a blinking reaction was recorded. Reflexes were assessed every $20 \mathrm{~s}$ from $\mathrm{T}=15 \mathrm{~s}$ onwards for all treatments until all reflex tests showed a negative response that was repeated sequentially three times and a flat EEG was recorded. In addition, reflexes were assessed $5 \mathrm{~s}$ after captive bolt stunning in calves of treatment 1 and 4 . Reflex tests were performed in a random order per calf.

\section{Data analyses}

EEG data were displayed, stored and analysed using PolyBench software (TMSI). EEG activity (amplitude and frequency) of each calf was visually assessed to determine the start of the following stages: baseline, transitional, unconscious and minimal brain activity. Figure 2 shows an example of a representative series of $5 \mathrm{~s}$ of EEG registration during these different stages. The baseline stage consisted of a low amplitude, high frequency signal, indicating alert calves (Figure 2a). The transitional stage is characterized by low frequency, high amplitude (firing of neurons in a synchronized fashion) becoming more apparent compared with baseline, associated with reduced consciousness (Figure 2b, McKeegan et al., 2013). When low frequency, high amplitude dominated the EEG trace this was interpreted to indicate unconsciousness (Figure 2c, Baars et al., 2003). Minimal brain activity was reflected by a flat signal $(<10 \%$ of baseline amplitude, Figure $2 \mathrm{~d}$ ). Time to loss of a reflex was defined as the first time at which a reflex showed a negative response that was repeated sequentially three times, since loss and return of a reflex was observed in some calves.

\section{Statistical analyses}

To calculate sample size, a power analysis was performed using the Power Calculation version 2.03 programme, designed by van Wilgenburg and van Schaick Zillesen, 2003 version. Results indicated that a sample of at least 10 calves per treatment would be required to detect a difference of $20 \mathrm{~s}$ in loss of consciousness with $90 \%$ power using a $t$-test between means with $\alpha$ at 0.05 . The sample size was 
(a)

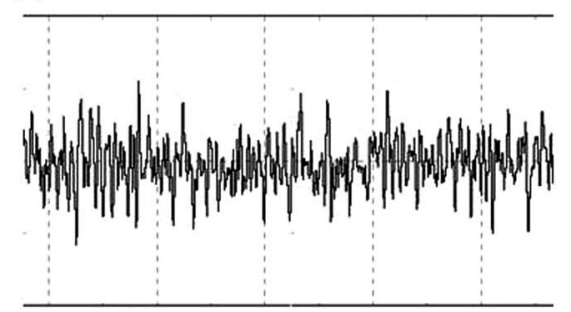

(c)

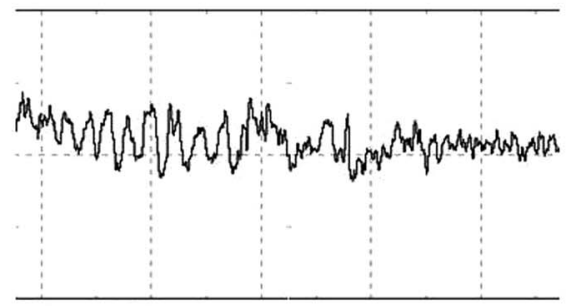

(b)

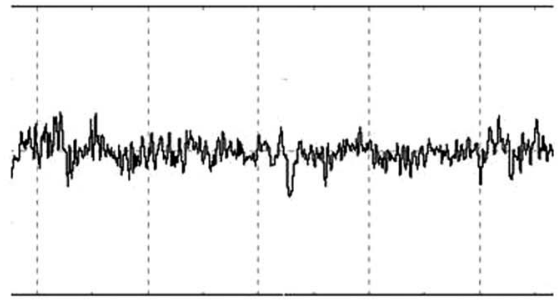

(d)

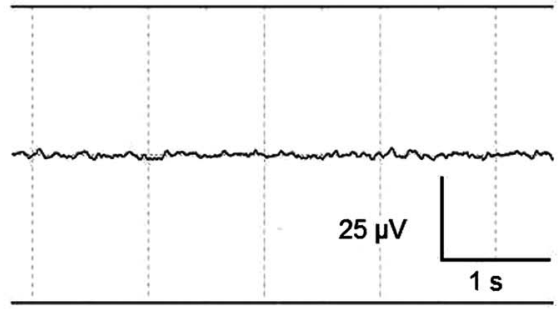

Figure 2 (a-d) Representative examples of the different stages identified with visual assessment of electroencephalogram (EEG) activity before and after stunned and non-stunned slaughter in calves. The four stages from left to right and top to bottom: baseline (a), transitional (b), unconscious (c), and minimal brain activity (d). Total $x$-axis represents $5 \mathrm{~s}$, y-axis represents amplitude of the EEG-trace $(\mu \mathrm{V})$.

increased to 25 calves per treatment to allow for possible loss of EEG recordings.

Statistical analyses were performed using SAS (version 9.3; SAS Institute, 2004). Normality of variance was checked (PROC UNIVARIATE) for all the variables examined. Before the analyses, the variables 'time to lost eyelid reflex' and 'time to lost corneal reflex' were log transformed to normalize the variance within these variables. In order to determine whether or not non-stunned slaughter in an upright or inverted position had a significant effect on time to onset of different EEG stages and time to loss of reflexes, data were analysed using a GLM procedure according to the model:

$$
Y_{i}=T_{i}+\varepsilon_{i}
$$

where $T_{i}$ is the treatment ( 2 and 3 ), and $\varepsilon_{i}$ the residual error term.

Stunned slaughter (treatments 1 and 4) was not taken into account in this procedure, since unconsciousness was immediately induced after stunning in these animals.

Differences were considered to be significant at the $5 \%$ probability level.

\section{Results}

\section{Animals}

The total number of calves used in this study was 82 . In one calf from treatment 4, the EEG signal was lost after stunning and consequently assessment of loss of consciousness was impossible. Data from this calf was excluded from further analyses.

\section{Electroencephalogram activity}

A clear EEG signal was obtained from all calves during baseline recordings. Based on EEG recordings, calves stunned with a captive bolt (treatment 1) were unconscious $1 \pm 0 \mathrm{~s}$ after stunning. No transitional stage was observed in these calves. One calf, however, lost consciousness $11 \mathrm{~s}$ after stunning based on EEG recordings. Minimal brain activity was observed in all calves from $22 \pm 19 \mathrm{~s}$ after stunning. Calves of treatments 2 and 3 developed a transitional EEG based on EEG recordings $54 \pm 13$ and $27 \pm 15$ s, respectively, after the neck cut. Calves of treatments 2 and 3 were considered unconscious based on EEG recordings $109 \pm 32$ and $49 \pm 25 \mathrm{~s}$, respectively, after the neck cut. Calves of treatments 2 and 3 had minimal brain activity based on EEG recordings $157 \pm 50$ and $86 \pm 34 \mathrm{~s}$, respectively, after the neck cut.

Figure 3 represents the percentage of calves displaying different EEG stages over time subjected to non-stunned slaughter in an upright position (treatment 2) or an inverted position (treatment 3 ) at $\mathrm{T}=0 \mathrm{~s}$. The time span for $80 \%$ or $100 \%$ of the calves to reach a transitional EEG, unconsciousness or minimal brain activity is displayed in Table 1 . Eighty per cent of the calves slaughtered in an upright position (treatment 2) lost consciousness on average $61 \mathrm{~s}$ later than calves slaughtered in an inverted position (treatment 3). All the calves slaughtered in an upright position (treatment 2) lost consciousness on average $31 \mathrm{~s}$ later than calves slaughtered in an inverted position (treatment 3 ).

Of the treatment 2 calves, $20 \%$ had a transitional EEG, none were considered unconscious and none had minimal brain activity based on EEG recordings $40 \mathrm{~s}$ after the neck cut. Of the treatment 3 calves, $81 \%$ of the calves had a transitional EEG, $46 \%$ were considered unconscious and $8 \%$ had minimal brain activity based on EEG recordings $40 \mathrm{~s}$ after the neck cut.

Treatment 4 calves (non-stunned slaughter in an upright position followed by captive bolt stunning) were stunned on average $34 \pm 8 \mathrm{~s}$ after the neck cut. At stunning, $67 \%$ of the calves were conscious, $8 \%$ of the calves had a transitional EEG, $21 \%$ of the calves were unconscious and $4 \%$ of the 
(a)

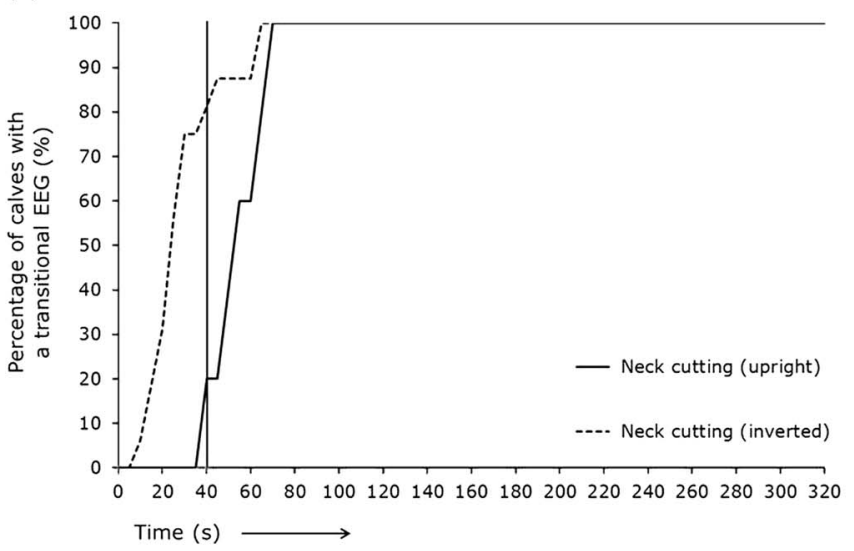

(b)

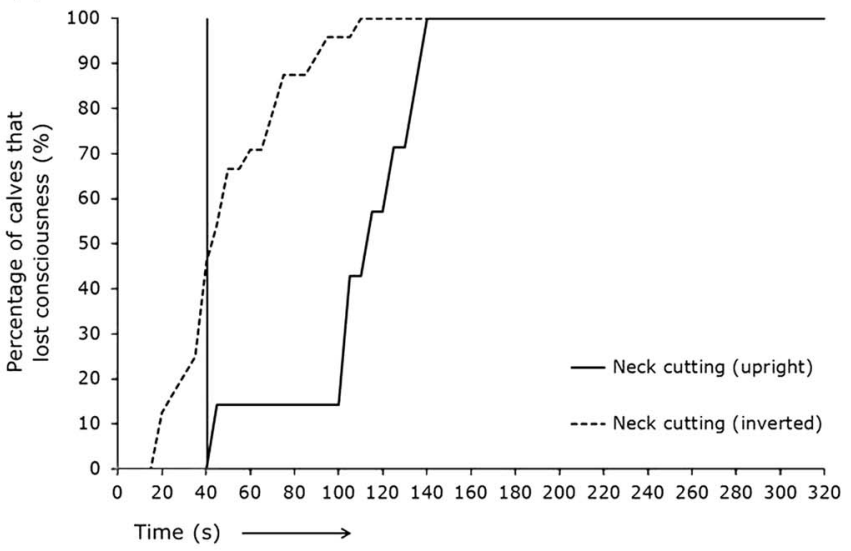

(c)

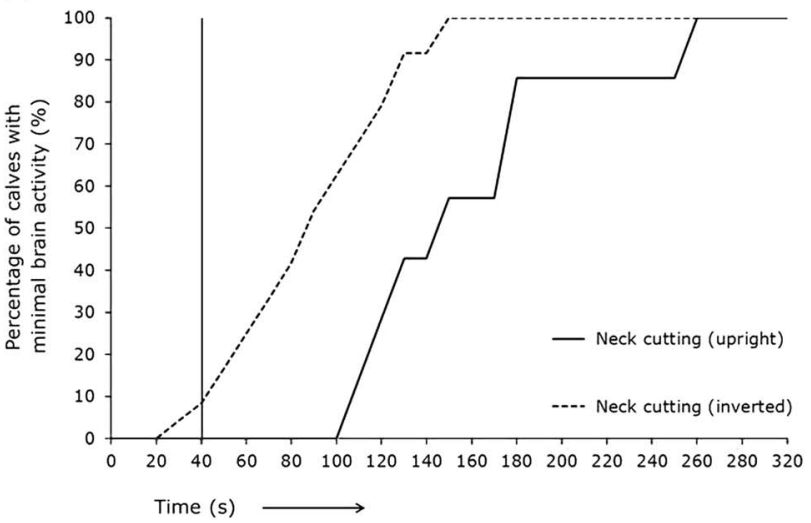

Figure $3(a-c)$ Percentage of calves with different electroencephalogram (EEG) stages through time after non-stunned slaughter in an upright position (red lines, $n=7$ ) or inverted position (blue lines, $n=25$ ) at $\mathrm{T}=0 \mathrm{~s}$. Vertical black line represents the percentage of calves with a specific EEG stage at $40 \mathrm{~s}$.

Table 1 Time points at which $80 \%$ or $100 \%$ of the calves subjected to non-stunned slaughter $(T=0 \mathrm{~s})$ in an upright $(\mathrm{n}=7)$ or inverted position $(\mathrm{n}=25)$ had a specific electroencephalogram (EEG) stage

EEG stage

with a specific EEG stage Transitional (s) Unconscious (s) Minimal brain activity (s) Transitional (s) Unconscious (s) Minimal brain activity (s)

\begin{tabular}{lrrrrrr}
$80(\%)$ & 62 & 132 & 175 & 36 & 71 & 122 \\
$100(\%)$ & 70 & 140 & 253 & 62 & 109 & 147 \\
\hline \hline
\end{tabular}

calves displayed minimal brain activity. All calves that were conscious or had a transitional EEG before stunning were unconscious $1 \pm 0 \mathrm{~s}$ after stunning based on EEG recordings.

\section{Loss of reflexes for unconsciousness}

Reflexes were tested and present in all calves during baseline recordings. In calves of treatment 1, threat-, withdrawal-, corneal- and eyelid reflex were all permanently lost at the first testing moment $(T=5 \mathrm{~s}$ ) after captive bolt stunning. Figure $4 a$ presents the range of individual time points at which the different reflexes were lost in relation to onset of the different EEG stages ( $T=0 \mathrm{~min}$ ), based on visual assessment of EEG recordings during non-stunned slaughter of calves in an upright position (treatment 2). In all treatment 2 calves, the threat-, and withdrawal reflex were both lost before EEG-based loss of consciousness had been observed. The corneal-, and eyelid reflex were both lost in all calves of treatment 2 after EEG-based loss of consciousness was observed. Corneal- and eyelid reflex were lost in $71 \%$ and $86 \%$, respectively, of calves of treatment 2 after onset of minimal brain activity.

Figure $4 \mathrm{~b}$ represents the range of individual time points at which the different reflexes were lost in relation to onset of the different EEG stages $(T=0 \mathrm{~min})$, based on visual assessment of EEG recordings during non-stunned slaughter of calves in an inverted position (treatment 3). In calves of 
(a)

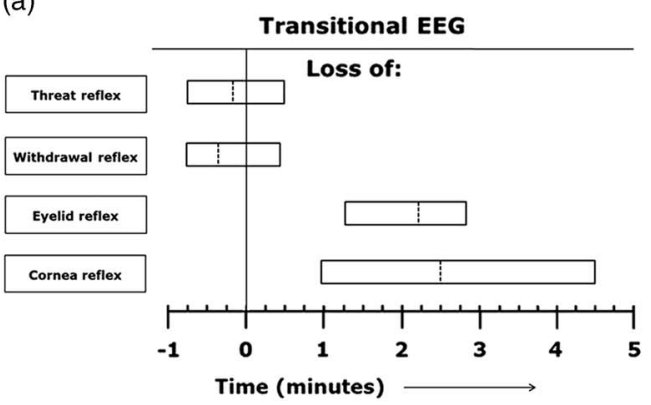

(b)

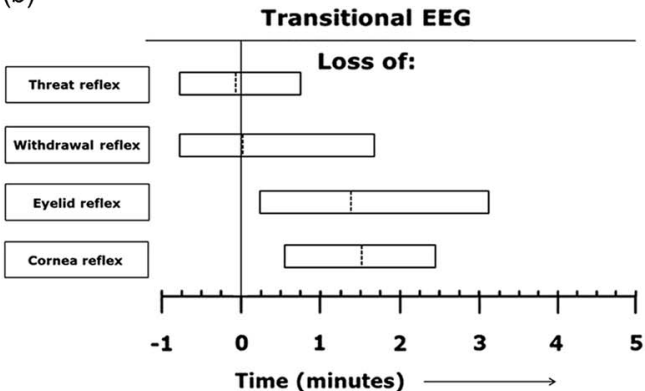

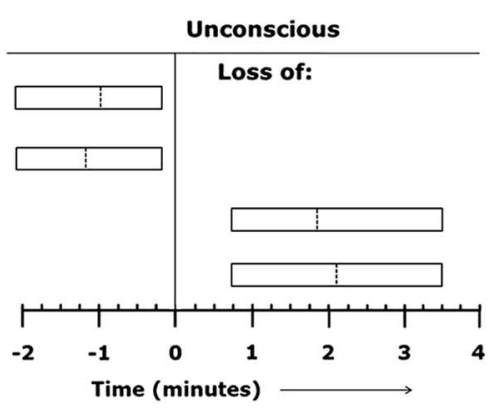
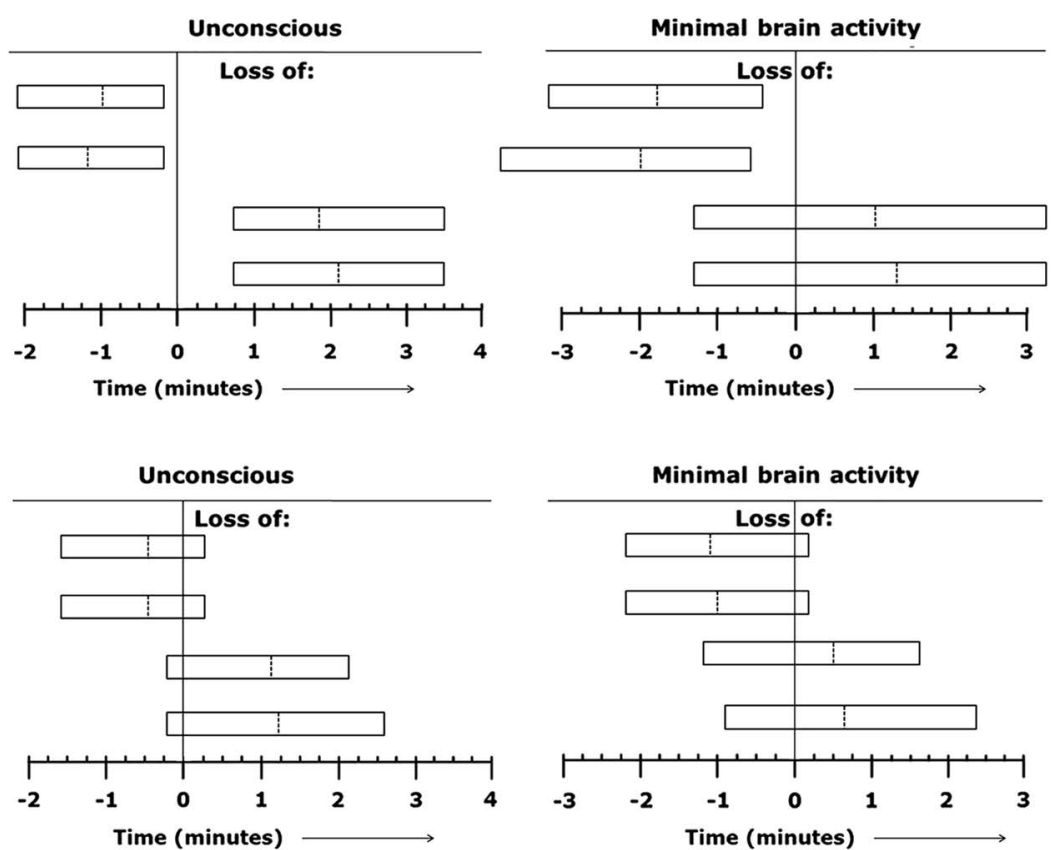

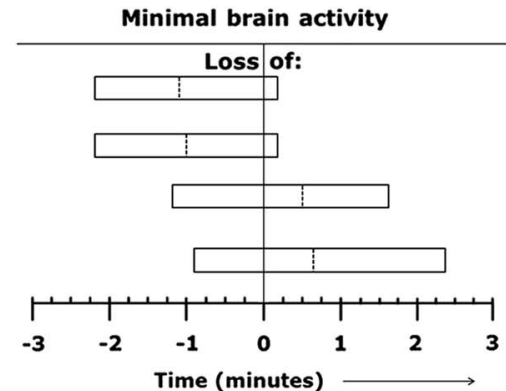

Figure $4(a, b)$ Range of individual time points at which the different reflexes are lost in relation to start of the different electroencephalogram (EEG) stages ( $\mathrm{T}=0 \mathrm{~min}$ ) based on visual assessment of EEG recordings during non-stunned slaughter of calves in an upright position $(n=7)$ (Figure 4a) and an inverted position $(n=25)$ (Figure 4b). Dotted lines indicate average values of all observations and left and right vertical lines of each block indicate minimum and maximum values for all observations.

treatment 3 , the threat- and withdrawal reflex were lost in $88 \%$ and $92 \%$ respectively, of the animals before EEG-based loss of consciousness was observed. Both corneal- and eyelid reflex were lost in $92 \%$ of calves of treatment 3 after EEG-based loss of consciousness had been observed. The threat- and withdrawal reflex were lost in $92 \%$ and $96 \%$, respectively, of calves of treatment 3 before minimal brain activity was observed. The corneal- and eyelid reflex were lost in $88 \%$ and $67 \%$, respectively, of calves of treatment 3 after minimal brain activity had been observed. Calves of treatments 2 and 3 lost the corneal reflex $235 \pm 86$ and $123 \pm 34 \mathrm{~s}$, respectively, after the neck cut. Calves of treatments 2 and 3 lost the eyelid reflex $218 \pm 65$ and $115 \pm 36 \mathrm{~s}$, respectively, after the neck cut.

All calves of treatment 4, lost both the threat- or withdrawal reflex before EEG-based loss of consciousness. The corneal- or eyelid reflex were lost in $89 \%$ and $87 \%$, respectively, of the calves after EEG-based loss of consciousness. The threat-, withdrawal-, corneal- and eyelid reflex were all permanently lost $5 \mathrm{~s}$ after the captive bolt stunning.

\section{Discussion}

The main aim of this study was to provide insight into the validity of certain reflexes that are used to assess unconsciousness at slaughter in veal calves, that is the threat-, withdrawal-, corneal- and eyelid reflex. Brain activity, as presented in an electroencephalogram or EEG, served as a 'gold standard' for our assessment of unconsciousness.

Consciousness involves the cerebral cortex and thalamus, together forming the thalamocortical complex, which is regulated by the brainstem. The central core of the brainstem is formed by the reticular formation, a large network of neural tissue located in the central region of the brain stem. Neuronal projections from the reticular formation to the cortex are called the ascending reticular activating system (ARAS). A good-functioning reticular formation and ARAS are essential for the maintenance of consciousness and damage to (one of) these regions causes rapid loss of consciousness. Unconsciousness induced by penetrating captive bolt stunning is caused by a combination of the concussive force generated by impact of the bolt on the cranium and irreversible physical damage produced by passage of the bolt through the brain. Generally, the pistol is placed on the forehead after which the bolt penetrates the skull to target the brain stem. Immediate loss of consciousness and reflexes should occur from the resulting trauma to the cerebral hemisphere and brain stem (Terlouw et al., accepted a). Depending on the method of stunning, the EEG shows a characteristic pattern of change when animals lose consciousness. Generally, an increase in low frequency activity is accompanied by an increase in amplitude. When neurons depolarize at the same time or frequency, they fire in a synchronized fashion creating slow high amplitude waves as seen in unconscious states suggesting a depression of the reticular formation (Lopes da Silva, 1983). EEG recordings in captive bolt stunned animals displayed high-amplitude, slow-frequency waves after stunning, indicating immediate unconsciousness, similar to findings of Lambooy and Spanjaard (1981) and Zulkifli et al. (2014). One calf in the current study displayed a period of baseline-like EEG activity, lasting for $11 \mathrm{~s}$ after captive-bolt stunning. This calf displayed 
a permanent loss of all reflexes from $5 \mathrm{~s}$ after stunning. Reflexes in the conscious calf before the beginning of the slaughter procedure were always present and it is therefore unlikely that these reflexes were lost, though the calf was conscious. The prolonged period of baseline-like EEG activity may have been caused by incorrect positioning of the stunner, a deflected shot, incorrect functioning of the stunning device itself or an ineffective EEG recording.

Effectively shot cattle should collapse immediately due to damage to the reticular formation that also plays a role in maintaining posture (Laureys and Tononi, 2009). In our study, an immediate collapse was observed in some of the calves, but tight restraining of the calf often prevented collapse and made observation of this criterion difficult. Five seconds after captive bolt stunning all reflexes were permanently lost in all calves. Rhythmic breathing and the righting reflex are considered indicative of a (partial) return of consciousness and thus that the stunning has not been irreversible (Grandin, 2002). Both rhythmic breathing and the righting reflex could not be assessed because the animals were fully restrained in a rotatory box.

Non-stunned animals that are subjected to neck cutting lose consciousness gradually as a consequence of widespread anoxia in the brain that results in progressive dysfunction of cortical and subcortical structures (Terlouw et al., accepted b). During our experiment, calves in an inverted or upright position lost consciousness, based on EEG recordings, $49 \pm 25$ and $109 \pm 32 \mathrm{~s}$, respectively (mean \pm SD), after the neck cut. Previous studies in cattle indicated loss of consciousness ranging from $10 \mathrm{~s}$ up to over $3 \mathrm{~min}$ after the neck cut (Daly et al., 1988; Gregory et al., 2010; Bourguet et al. 2011). Newhook and Blackmore (1982) suggested the possibility of an intermittent return to consciousness for up to 123 to $323 \mathrm{~s}$ after non-stunned slaughter in cattle. Detailed study of EEG recordings did not indicate signs of resurgence of consciousness in any of the calves in our study. The corneal- and eyelid reflex, however, were lost and regained in $9 \%$ and $16 \%$, respectively, of the non-stunned calves $(n=32)$ during bleeding. Loss and return of the corneal reflex has been observed by Hoffman in an unspecified number of cattle (Hoffman, 1900 cited by Gregory et al. 2010). Bourguet et al. (2011) also observed a temporary return of the palpebral and corneal reflex in some of the non-stunned slaughtered cattle. A temporary return of blood pressure would be necessary for these reflexes to return and may possibly be explained by physiological changes, such as an increased heart rate, to alleviate the drop in blood pressure (Newhook \& Blackmore, 1982; Vimini et al., 1983). There is no clear indication why reflexes were regained and lost again in some of the calves in the current experiment.

Because this experiment took place at a commercial slaughter plant, the slaughter man was empowered to decide when an additional cut was necessary. No clear criteria were defined for this. In total 15 of $82(18 \%)$ calves in our study were cut a second time and one of those 15 calves was cut a third time. The arteries of an animal in which poor bleeding is observed, are in practice often re-cut to allow adequate bleeding. Poor bleeding may be caused by occlusion, which is characterized by retraction and contraction of the elastic portion of the arterial wall and thrombus formation around the severed end of the vessel (Gregory et al., 2006). The prevalence of carotid arterial occlusion in 576 cattle slaughtered at abattoirs in the United Kingdom was found to be $16 \%$ and $25 \%$, respectively, for adult cattle and bobby calves (Gregory et al., 2006). A study by Gregory et al. (2010) showed that $71 \%$ of cattle taking longer than $75 \mathrm{~s}$ to collapse, had a false aneurysm in the cardiac end of the carotid that was at least $3 \mathrm{~cm}$ in diameter. There was no further investigation into the background of this obstruction, but it may provide an explanation for the large variation in time to loss of consciousness between calves.

Duration to loss of consciousness was $50 \mathrm{~s}$ longer in non-stunned veal calves restrained upright than by those restrained in an inverted position. During this experiment, all calves were slaughtered in the same rotation box which normally is used for inverted slaughter. Hence, slaughter using a box designed for upright restraint may provide different results. Blood flow in calves slaughtered upright was often obstructed when the head fell limp against the head restrainer. Based on this observation and in consideration of the potential risk to animal welfare, the number of veal calves slaughtered non-stunned in an upright position was limited to seven calves. Inversion of cattle for slaughter in itself is widely debated and thought to cause distress because of a longer delay between entering the restrainer and full restraint. In addition there is discomfort from the inverted position resulting in hypoxemia and rumen pressure on the diaphragm (Dunn, 1990; Petty et al., 1994; Tagawa et al., 1994). Another potential welfare problem is aspiration of blood and refluxing gut content after neck cutting in nonstunned animals (EFSA, 2004). Though the latter problem is mainly associated with the inverted position, it has also been observed in non-stunned slaughtered calves in the upright position (Grandin and Regenstein, 1994; Gregory et al., 2009). A report by the Farm Animal Welfare Committee (2012) stated that there is little evidence of any welfare advantages of inversion in terms of speed and efficiency of the cut. Visits to 18 European cattle slaughter plants showed that the mean number of cuts was higher for cattle restrained in an upright position than those in other restraining systems (Dialrel, 2010). Although others claim, that the angle of the head in inverted cattle allows for a more effective downward cut compared to the upward cut in animals in an upright position (Slaughter of Animals (prevention of cruelty) Regulations 1958 - quoted by Dunn, 1990). The present study is, to our knowledge, the first to suggest that the neck cut may be more effective in terms of duration to loss of consciousness in non-stunned slaughtered animals in an inverted position.

Reflexes in non-stunned slaughtered animals were not lost immediately, as in captive bolt stunned animals, but disappeared gradually. Generally, the threat reflex and withdrawal reflex were lost first, followed by the cornealand eyelid reflex. Loss of reflexes in this order may be 
dependent on the difference in resistance to anoxia by different parts of the brain. Functions that rely on integration of cortical processes are more susceptible to anoxia than those originating from lower brain structures, such as the brain stem (Hansen, 1985). On average, the threat reflex was lost in non-stunned calves before EEG-based unconsciousness. The rapid loss of the threat reflex can possibly be explained by the sudden drop in blood flow after neck cutting causing hypoxia of the brain cells involved (Bourguet et al., 2011). A similar phenomenon was also observed for the withdrawal reflex that was lost on average before EEG-based loss of consciousness. When the neck is cut, the knife transects veins, arteries and other blood vessels, skin, muscle, trachea, oesophagus, sensory- and motor nerves, and connective tissue. Transecting these soft tissues will send a considerable amount of neural impulses to the brain (Gregory, 2004). The massive stimulation of all sensory nerves after the neck cut may overrule the neural input from other, milder sources of pain, such as pinching the nose. Opinions on pain perception during neck cutting are divided. Some (e.g. Grandin, 1994; Rosen, 2004) state that use of an exquisitely sharp knife, will prevent pain after the neck cut. Others (e.g. Gibson et al., 2007 and 2009; Mellor et al., 2009) state that the ventral neck cut is a noxious stimulus and that there is strong evidence that this cut would be perceived as painful from the time of the neck cut until loss of consciousness. Until now, neurophysiological methodology has not provided a final and definitive answer to this issue.

Both the corneal- and eyelid reflex require a functional afferent cranial nerve $V$ (trigeminal) and efferent cranial nerve VII (facial) and the relevant eye muscles to function adequately (Adams and Sheridan, 2008). The connections between the spinal trigeminal- and facial nuclei pass through the reticular formation and failure of these reflexes often indicates a wider dysfunction of the brain, comprising part of the reticular formation, and thus a state of unconsciousness (Terlouw et al., accepted b). In the present study, the corneal reflex in non-stunned slaughtered calves was lost on average $85 \pm 45 \mathrm{~s}$ after EEG-based loss of consciousness and on average $47 \pm 63 \mathrm{~s}$ after minimal brain activity was observed. Lambooij et al. (2012) and Newhook and Blackmore (1982) observed that non-stunned slaughtered calves lost the corneal reflex up to $1 \mathrm{~min}$ after calves were unconscious (EEG-based) and this reflex was even observed in some calves after all EEG activity had been lost. Verhoeven et al. (2015b) observed that non-stunned slaughtered sheep lost the corneal reflex on average 00:59 \pm 00:17 min (mean $\pm S D$ ) after sheep were considered to be unconscious based on EEG recordings. The eyelid reflex in non-stunned slaughtered calves was lost on average $76 \pm 50 \mathrm{~s}$ after EEG-based loss of consciousness and $37 \pm 59 \mathrm{~s}$ after minimal brain activity was observed. Other studies report the presence of an eyelid reflex in unconscious sheep (Verhoeven et al., 2015b) and cattle (Newhook and Blackmore, 1982) and also during anaesthesia. The eyelid reflex is known to be present after an animal is considered unconscious (Dugdale, 2010). The order in which the eyelid- and corneal reflex cease may differ, providing uncertainty which reflex is more resistant to the effects of anoxia (Bourguet et al., 2011; Terlouw et al., accepted b).

The results from this study support the hypothesis that a positive corneal- or eyelid reflex alone does not necessarily indicate consciousness, since positive brain stem reflexes might occur on the basis of residual brain stem activity and do not distinguish clearly between consciousness and unconsciousness (Anil, 1991). Consequently, a negative corneal- or eyelid reflex is considered a general indication of unconsciousness (Laureys, 2005; Terlouw et al., accepted b).

\section{Conclusions}

In both stunned and non-stunned calves, unconsciousness was induced and absence and presence of reflexes was successfully linked to EEG activity. The use of reflexes to assess unconsciousness can more easily be applied in daily practice, and EEG recordings can be used to validate the interpretation of such reflexes. After captive bolt stunning, absence of threat-, withdrawal-, corneal- and eyelid reflex indicated unconsciousness as determined by EEG recordings. On average, after non-stunned slaughter, the threat- and withdrawal reflex were lost before calves were considered unconscious based on EEG recordings. The eyelid- and corneal reflex were on average lost after calves were considered unconscious based on EEG recordings and appeared to be distinctly conservative indicators of unconsciousness in non-stunned slaughtered calves since they were observed up to $76 \pm 50$ and $85 \pm 45 \mathrm{~s}$ (mean $\pm S \mathrm{SD}$ ) respectively after EEG-based onset of unconsciousness.

\section{Acknowledgements}

The authors would like to thank Vincent Hindle and Samantha Surquin for their support while collecting the data. Jan Peuscher is acknowledged for his technical assistance while collecting the data and his help during data analyses. The authors also acknowledge the owner and employees of the slaughter plant for their assistance and hospitality during the study. Funding for this project was provided by the Dutch Ministry of Economic Affairs (KB-12-006.01-002).

\section{References}

Adams DB and Sheridan AD 2008. Specifying the risks to animal welfare associated with livestock slaughter without induced insensibility. Retrieved on 19 November 2013 from http://www.australiananimalwelfare.com.au/app/ webroot/files/upload/files/animal-welfare-livestock-slaughter.pdf

Anil MH 1991. Studies on the return of physical reflexes in pigs following electrical stunning. Meat Science 30, 13-21.

Baars BJ, Ramsøy TZ and Laureys S 2003. Brain, conscious experience and the observing self. Trends in Neurosciences 26, 671-675.

Bager F, Braggins T, Devine C, Graafhuis A, Mellor D, Tavener A and Upsdell M 1992. Onset of insensibility at slaughter in calves: effects of electroplectic seizure and exsanguination on spontaneous electrocortical activity and indices of cerebral metabolism. Research in Veterinary Science 52, 162-173.

Baldwin B and Bell F 1963. The effect of temporary reduction in cephalic blood flow on the EEG of sheep and calf. Electroencephalography and Clinical Neurophysiology 15, 465-473.

Bourguet C, Deiss V, Tannugi CC and Terlouw E 2011. Behavioural and physiological reactions of cattle in a commercial abattoir: relationships with 
organisational aspects of the abattoir and animal characteristics. Meat Science $88,158-168$.

Council Regulation (EC) No 1099/2009 2009. Council Regulation No1099/2009 on the protection of animals at the time of killing. Official Journal of the European Union L303, 1-30.

Daly C, Kallweit E and Ellendorf F 1988. Cortical function in cattle during slaughter: conventional captive bolt stunning followed by exsanguination compared with shechita slaughter. The Veterinary Record 122, 325-329.

Dialrel 2010. WP2.2. Religious slaughter: Evaluation of current practices. Retreived on 4 September 2015 from http://dialrel.eu/images/factsheetpractice.pdf

Dugdale A 2010. Veterinary anaesthesia: principles to practice. Blackwell Publishing Ltd, Chichester, West-Sussex, UK.

Dunn C 1990. Stress reactions of cattle undergoing ritual slaughter using two methods of restraint. Veterinary Record 126, 522-525.

Erasmus MA, Turner PV and Widowski TM 2010. Measures of insensibility used to determine effective stunning and killing of poultry. Journal of Applied Poultry Research 19, 288-298.

European Food and Safety Authority (EFSA) 2004. Welfare aspects of stunning and killing methods. Scientific report of the scientific panel of animal health and welfare on a request from the commission. Question EFSA Q 2003-093. Adopted on the 15th June 2004. Bruxelles, Belgium.

European Food and Safety Authority (EFSA) 2013. Scientific opinion on monitoring procedures at slaughterhouses for bovines. EFSA Journal 11, 3460-3525. Farm Animal Welfare Committee (FAWC) 2012. FAWC advice on cattle inversion for religious slaughter (independent report). Retrieved on 26 January 2015 from https://www.gov.uk/government/uploads/system/uploads/attachment_data/file/ 325002/FAWC_advice_on_cattle_inversion_for_religious_slaughter.pdf

Farouk MM 2013. Advances in the industrial production of halal and kosher red meat. Meat Science 95, 805-820.

Gibson TJ, Johnson CB, Murrell JC, Hulls CM, Mitchinson SL, Stafford KJ, Johnstone AC and Mellor DJ 2009. Electroencephalographic responses of halothane anaesthetised calves to slaughter by ventral-neck incision without prior stunning. New Zealand Veterinary Journal 57, 77-83.

Gibson TJ, Johnson CB, Stafford KJ, Mitchinson SL and Mellor DJ 2007. Validation of the acute electroencephalographic responses of calves to noxious stimulus with scoop dehorning. New Zealand Veterinary Journal 55, 152-157.

Grandin T 1994. Euthanasia and slaughter of livestock. Journal of the American Veterinary Medical Association 204, 1354-1360.

Grandin T 2002. Return-to-sensibility problems after penetrating captive bolt stunning of cattle in commercial beef slaughter plants. Journal of the American Veterinary Medical Association 221, 1258-1261.

Grandin T and Regenstein JM 1994. Religious slaughter and animal welfare: a discussion for meat scientists. Meat Focus International 3, 115-123.

Gregory NG 2004. Physiology and behaviour of animal suffering (UFAW Animal Welfare Series). Blackwell Publishing, Oxford, UK.

Gregory N, Fielding H, Von Wenzlawowicz M and Von Holleben K 2010. Time to collapse following slaughter without stunning in cattle. Meat Science 85, 66-69.

Gregory N, Shaw F, Whitford J and Patterson-Kane J 2006. Prevalence of ballooning of the severed carotid arteries at slaughter in cattle, calves and sheep. Meat Science 74, 655-657.

Gregory N, Wenzlawowicz Mv and Von Holleben K 2009. Blood in the respiratory tract during slaughter with and without stunning in cattle. Meat Science 82, 13-16. Hansen AJ 1985. Effect of anoxia on ion distribution in the brain. Physiological Reviews 65, 101-148.
Lambooij E, van der Werf J, Reimert $\mathrm{H}$ and Hindle V 2012. Restraining and neck cutting or stunning and neck cutting of veal calves. Meat Science 91, 22-28.

Lambooy E and Spanjaard W 1981. Effect of the shooting position on the stunning of calves by captive bolt. The Veterinary Record 109, 359-361.

Laureys S 2005. Science and society: death, unconsciousness and the brain. Nature Reviews. Neuroscience 6, 899-909.

Laureys S and Tononi G 2009. The neurology of consciousness: cognitive neuroscience and neuropathology, 1st edition. Academic Press, London, UK.

Lopes da Silva FH 1983. The assessment of unconsciousness: general principles and practical aspects. In Stunning of animals for slaughter (ed. G Eikelenboom), pp. 3-12. Martinus Nijhoff Publishers, The Hague, the Netherlands.

McKeegan D, Reimert H, Hindle V, Boulcott P, Sparrey J, Wathes C, Demmers $T$ and Gerritzen M 2013. Physiological and behavioral responses of poultry exposed to gas-filled high expansion foam. Poultry Science 92, 1145-1154.

Mellor D, Gibson T and Johnson C 2009. A re-evaluation of the need to stun calves prior to slaughter by ventral-neck incision: an introductory review. New Zealand Veterinary Journal 57, 74-76.

Nangeroni $L$ and Kennett $P$ 1963. An electroencephalographic study of the effect of shechita slaughter on cortical function in ruminants. Ithaca University, Ithaca. Newhook JC and Blackmore DK 1982. Electroencephalographic studies of stunning and slaughter of sheep and calves: part 2 - the onset of permanent insensibility in calves during slaughter. Meat Science 6, 295-300.

Petty D, Hattingh J, Ganhao M and Bezuidenhout L 1994. Factors which affect blood variables of slaughtered cattle. Journal of the South African Veterinary Association 65, 41-45.

Rosen S 2004. Physiological insights into Shechita. Veterinary Record 154, 759-765.

Staatscourant 2012. Convenant onbedwelmd slachten volgens religieuze riten. Retrieved on 13 January 2015 from http://www.rijksoverheid.nl/documenten-enpublicaties/convenanten/2012/06/05/convenant-onbedwelmd-slachten-volgensreligieuze-riten.html

Tagawa M, Okano S, Sako T, Orima H and Steffey EP 1994. Effect of change in body position on cardiopulmonary function and plasma cortisol in cattle. The Journal of Veterinary Medical Science/the Japanese Society of Veterinary Science 56, 131-134.

Terlouw EMC, Bourguet C and Deiss V (accepted a). Consciousness, unconsciousness and death in the context of slaughter. Part 1. Neurobiological mechanisms underlying stunning and killing. Meat Science.

Terlouw EMC, Bourguet C and Deiss V (accepted b). Consciousness, unconsciousness and death in the context of slaughter. Part 2. Evaluation methods. Meat Science.

Verhoeven M, Gerritzen M, Hellebrekers L and Kemp B 2015a. Indicators used in livestock to assess unconsciousness after stunning: a review. Animal 9, 320-330.

Verhoeven M, Gerritzen M, Kluivers-Poodt M, Hellebrekers L and Kemp B 2015b. Validation of behavioural indicators used to assess unconsciousness in sheep. Research in Veterinary Science 101, 144-153.

Vimini R, Field R, Riley M and Varnell T 1983. Effect of delayed bleeding after captive bolt stunning on heart activity and blood removal in beef cattle. Journal of Animal Science 57, 628-631.

Zulkifli I, Goh Y, Norbaiyah B, Sazili A, Lotfi M, Soleimani A and Small A 2014. Changes in blood parameters and electroencephalogram of cattle as affected by different stunning and slaughter methods in cattle. Animal Production Science 54, 187-193. 